\title{
Anne L. C. Runehov, The Human Being, the World and God. Studies at the Interface of Philosophy of Religion, Philosophy of Mind and Neuroscience (Uppsala: Springer International Publishing Switzerland, 2016, pp. 174)
}

DOI: http://dx.doi.org/10.12775/RF.2019.064

The first question is what is human being. The second one is what is it to be a human being. The last question became: can it, in the age of science, still be argued that there is something special or specific about being human?*

The three questions cited above summarise the main aim of Anne L. C. Runehov in her book on religion, philosophy and neuroscience, which this review concerns. The author makes an attempt to answer those questions by tackling complex issues and problems from the borderline of ontology, philosophy of religion, philosophy of mind, theory of mind, and, last but not least, neurology.

The book is divided into three parts, namely "Part I. Human being", "Part II. The World", "Part III. God"; however, one may find oneself under a strong impression that it is actually a two-part work. Roughly speaking, the first half of the book is devoted to the topic of human being, concerning both the philosophical and the neurological aspects of what it means to be "human." The rest of the work then presents

* Anne L. C. Runehov, The Human Being, the World and God. Studies at the Interface of Philosophy of Religion, Philosophy of Mind and Neuroscience (Uppsala: Springer International Publishing, 2016), viii. 
a more religion-focused point of view, discussing and analysing who or what is that "ultimate being" some may call "God", and how this being is related to the world we live in. Thus, holistically, the book may be defined as well as a piece of philosophical literature with a little addition of the selected neurological facts about the human nature.

Prof. Anne L. C. Runehov is a Swedish theologian, a philosopher of religion, and an academic at the Copenhagen University in Sweden. In the "Preface", the author claims that it had been nine years now (in 2016) since her first book, entitled Sacred or Neural? The Potential of Neuroscience to Explain Religious Experience, which was already an indication of her interest in connecting religious experiences with neurological aspects of human organism. Then, she became the author and the editor of the Encyclopedia of Science and Religion before she started working on the book this review concerns. As far as I am aware, The Human Being, the World and God. Studies at the Interface of Philosophy of Religion, Philosophy of Mind and Neuroscience was not translated into English by any specialist in translations, which means that the author wrote it in English by herself. If it is so, one may claim that, evidently, she encountered some linguistic difficulties during the process of creating the content. Namely, the text is not free of minor and, occasionally, major mistakes. My goal is not to list all of the mistakes I have noticed since I am not a native speaker of English myself, but it is just to mention that the overall reception of the text can be hindered by some flaws (especially when the reader is a non-native user of that language).

She starts her discussion on the nature of human being from the presentation of what "being" is from the ontological point of view. She briefly mentions the terms of ens and esse to differentiate between "a being", which is "something that does the act of being" and "being", which means "the way in which ens is." It may seem to be fairly complicated, but Paul Horrigan (2017) provides much clearer explanation in this matter. Thus, one can say that:

Being (ens) is the present participle of the verb 'to be' (Latin: esse) and we say that being (ens) signifies a thing in so much as it is, somewhat in the same way that a 'swimmer' designates a person who swims, or a 'painter,' someone who paints, or a 'student,' designating someone who studies. ${ }^{1}$

So, our ens in Anne L. C. Runehov's book may be simply understood as "a human being". The author claims that "humans are experiencers", which suggests that she focuses more on our senses. In other words, she

1 Paul G. Horrigan, "Being (Ens), Essence (Essentia), and the Act of Being (Esse)," Academia.edu, 2017, access 17.03.2019, https://www.academia.edu/9966443/, 1.

2 Runehov, 41. 
states that living a human life means to experience the world. Moreover, she adds that each living being's life is a chain of experiences. Now, the question seems to emerge naturally: how humans are unique in their "experiencing"? Here we have the presentation of the notion of esse in Runehove's understanding. According to Horrigan, "the act of being (esse) is that which makes a thing to be", so this is what makes also humans $b e$. This is also how Runehov explains that difference, although she emphasizes the fact that humans are capable of experiencing, being also aware of that capability and understanding it, which, according to her, make humans so unique when compared to other species on Earth.

She connects the philosophical notion of esse with the neocortex developed in humans, and then she states that this feature gives us access to more complex experiences. One cannot disagree on that matter, but in my opinion, this point of view may be somehow unjust at least for some of us. What I mean here are people unable to experience at all. For example, patients in coma or suffering from deep paralysis may not be able to "interact" with their surroundings, which can question their ability to experience anything. There is also a statement in the book being reviewed here that humans "cannot not choose", albeit it may pose a difficult challenge if one was to argue that the abovementioned individuals have any choice, indeed. According to the rules and definitions presented by Anne L. C. Runehov, the rules would exclude the severely paralysed as well as those in coma from the group of beings who can be rightly called "humans." Having also in mind that the author seems to support Aristotle in his theory on the hierarchy of souls, one may reach the conclusion that the people "detached" from the world (as in the examples provided above) have a very good chance to be "downgraded" to the world of animals or even plants (namely "the vegetative soul"3).

Going back to the notion of esse, as it was said before, Runehov claims that the "way" in which humans beings "are" is experiencing. Furthermore, with their neocortex developed to the extent that no other species present, they are able to experience the "Ultimate reality". Simple as it is, at this point the author thinks of that specific being whom some may call God. This is what the majority of the content of the said book focuses on. I find significant difficulties trying not to discredit this point of view because of the extrapolation the author commits here. Having discussed different philosophical standings, and, what is more, possessing the knowledge of the way in which the human neural system functions, Anne L. C. Runehov does not seem to be willing to refrain from drawing long-range interpretations concerning issues, such as religion and ontology. I agree that humans are, in some way, unique comparing to other species and animals, but I am not sure whether the border between

\footnotetext{
${ }^{3}$ Ibidem, xviii.
} 
humans as the unique, superior beings and the rest of the inhabitants of Earth can be so easily defined (just to mention the patients in coma).

Extraordinarily non-scientific (and non-philosophical as well) is the part of the book where the author describes various examples of neardeath experience (NDE). I am aware that such phenomena exist, but I also know that there is an impressive number of studies which analyse those unique experiences in controlled settings. All of them show that religious experiences and meditational states of mind are strongly correlated with the activation of specific areas in human brain, e.g. the prefrontal cortex. Discussing the notion of "Ultimate reality", the author touches upon the topic of people who experienced that unique "journey" and "came back". There are several different individuals whom she describes in the said part of the book. She seems to be completely sure that the coincidence of the feelings and memories of such events is not accidental and, to increase the level of uniqueness of those phenomena, she marks that even those who claim to be atheists experienced near-death states in a fashion similar to that of the believers. I must agree that it may be perceived as something extraordinary, and it is, indeed. However, this is only because of relatively similar functioning of our brains. The prefrontal cortex is known to be responsible for the state of conscious awareness ${ }^{4}$ and "higher-level" feelings, such as guilt, and more. Not to mention that MRI scanners can easily explain that "strange" phenomenon so many claim to have experienced in their life. The author seems to be under a strong influence of the point of view she apparently supports. Later, she also refers to the finding that women tend to have more of such unusual experiences, namely - they have "been there" more often than men. At this point the author decides to confess that she is not knowledgeable enough to answer the question why it is so. It is a shame that she has not looked for more specific data and information on the NDE because she might have found useful details regarding this issue. Perhaps it would contribute to a slight change of the style in which the reviewed book was written.

On the other hand, The Human Being, the World and God. Studies at the Interface of Philosophy of Religion, Philosophy of Mind and Neuroscience also includes more scientific data on the ontology of human beings when the author compares people to "social animals", and I cannot find any incoherence in those parts of the text. She refers to certain studies, she cites scientific research findings, and she incorporates all the information in the suitable fragments of the content of her book. The only problem here is the contrast which is bound to strike a careful reader as one may

${ }^{4}$ Regina C. Lapate et al., "Awareness of Emotional Stimuli Determines the Behavioral Consequences of Amygdala Activation and Amygdala-Prefrontal Connectivity." Scientific Reports 6 (2017): 2. 
notice the change of the author's style, which "swings" from the one typical of a slight idealistic theologian to that of a more rational researcher and neuroscientist. In some parts, the book seems to have been written by two different individuals to accelerate its completion.

As for the psychological-philosophical part of the content of the reviewed book, it involves a fragment in which Anne L. C. Runehov discusses the issue of collective intentionality. Citing well-known specialists in the field, e.g. Daniel Denett or John Searle, she presents a fairly wide perspective on the mentioned matter. This part of the book is largely a review of the most popular points of view on the collective intentionality problem. In my opinion, the whole work would leave a neutral reader with much better sense of understanding if such a style was to be maintained throughout all of the chapters. I must agree that in some cases this phenomenon, which comes from the verge of the theory of mind, may truly suggest the actual uniqueness of human cognitive systems in comparison with some other species. Some animals, such as chimpanzees (e.g. bonobo) present behaviour patterns which may make one think that their cognitive processes are somehow very similar to those of Homo sapiens. However, those are only speculations as scientists have not discovered any reliable way to determine whether their hypotheses are true for they are not able to "ask" their subjects about their internal states even if they can train them to understand some basic patterns of communication. Self-awareness and self-reflection are very complex issues. Evolutionary psychologist try to tackle that problematic matter with different results. Michael Tomasello, ${ }^{5}$ for example, is one of the most significant researchers in this field with his analyses of the collective intentionality in apes and humans.

In conclusion, I must admit that Anne L. C. Runehov's The Human Being, the World and God. Studies at the Interface of Philosophy of Religion, Philosophy of Mind and Neuroscience is genuinely an interesting piece of literature as it addresses the title problem from various perspectives. The whole structure of the book is organised in some sort of a framing device by means of which its first as well as last part concerns philosophical polemics, namely what it means to "be", and, more specifically, what it is to be a "human being", which one can find at the beginning of the book, and then what the nature of that "Being" some call "God" is, and how that Being acts, that is - how it manifests its own act of being when referring to the notion of ens and esse, from which the whole discussion presented in this book actually starts. So, as one can easily notice, the content of the reviewed book is neatly put together in a manner

${ }^{5}$ Michael Tomasello, Historia naturalna ludzkiego myślenia [A Natural History of Human Thinking], transl. Bartłomiej Kucharzyk \& Rafał Ociepa (Kraków: Copernicus Center Press, 2015). 
that helps the readers to follow the author's train of thoughts. Nevertheless, different flaws and lack of a sufficient amount of information in several fragments may contribute to the disorganisation of the process of cognitive reception of the content presented in this book. That is why I advise carefulness in approaching this piece of literature, whether one would want to do this for the purpose of his or her work (academic or any other), or simply as one's leisure activity.

Bartosz Bukatko

Nicolaus Copernicus University, Toruń ORCID: 0000-0003-1902-2982 e-mail: b.b.bukot@gmail.com 